\title{
Novel evaluation scale for QOL (QOL-ACD-BP) in preoperative chemotherapy for breast cancer
}

\author{
Koji Takada ${ }^{1}$. Shinichiro Kashiwagi ${ }^{1}$ (1) Wataru Goto ${ }^{1} \cdot$ Yuka Asano $^{1} \cdot$ Katsuyuki Takahashi $^{2} \cdot$ Tamami Morisaki $^{1}$. \\ Tsutomu Takashima ${ }^{1} \cdot$ Shuhei Tomita $^{2} \cdot$ Kosei Hirakawa $^{1} \cdot$ Masaichi Ohira ${ }^{1}$
}

Received: 9 April 2018 / Accepted: 16 May 2018 / Published online: 19 May 2018

(C) The Author(s) 2018

\begin{abstract}
Purpose Quality-of-life (QOL) has been reported to affect the prognosis of many types of cancer, and several studies used various QOL assessment tools to determine the relationship between QOL and cancer prognosis. In this study, QOLQuestionnaire for Cancer Patients Treated with Anti-Cancer Drugs-the Breast (QOL-ACD-B) was modified to be suitable for preoperative chemotherapy (POC) and was named the QOL-ACD-BP.

Methods A total of 300 patients were treated with POC after being diagnosed with breast cancer between February 2007 and December 2016 at our institute. We evaluated novel evaluation scale for QOL (QOL-ACD-BP) before and after POC in a retrospective manner.

Results In the multivariate analysis with overall survival, the high QOL before [ $p=0.048$, hazard ratio (HR) 0.441$]$ or after POC ( $p=0.030$, HR 0.273) was an independent factor.

Conclusion Our study shows that QOL after POC may also affect prognosis and supported the importance of maintaining QOL in cancer treatment. In patients with breast cancer treated with POC, QOL-ACD-BP, which is a new QOL evaluation index, was found to be a useful tool for predicting the patients' prognosis.
\end{abstract}

Keywords Quality of life · Breast cancer · Prognostic marker · Preoperative chemotherapy · QOL-ACD-B

\section{Introduction}

Recently, psychological and social background as well as therapeutic effects and side effects have become important considerations in selecting cancer treatment (Howell et al. 2015). Quality-of-life (QOL) is the sum of the physical,

Electronic supplementary material The online version of this article (https://doi.org/10.1007/s00432-018-2670-0) contains supplementary material, which is available to authorized users.

Shinichiro Kashiwagi

spqv9ke9@view.ocn.ne.jp

Koji Takada

taka.cl22.kou.sp@gmail.com

Wataru Goto

saraikazemaru@gmail.com

Yuka Asano

asnyk0325@yahoo.co.jp

Katsuyuki Takahashi

k.taka@med.osaka-cu.ac.jp

Tamami Morisaki

spitz4_5@yahoo.co.jp

Tsutomu Takashima

tsutomu-@rd5.so-net.ne.jp

\author{
Shuhei Tomita \\ tomita.shuhei@med.osaka-cu.ac.jp \\ Kosei Hirakawa \\ hirakawa@med.osaka-cu.ac.jp \\ Masaichi Ohira \\ masaichi@med.osaka-cu.ac.jp \\ 1 Department of Surgical Oncology, Osaka City University \\ Graduate School of Medicine, 1-4-3 Asahi-machi, \\ Abeno-ku, Osaka 545-8585, Japan \\ 2 Department of Pharmacology, Osaka City University \\ Graduate School of Medicine, 1-4-3 Asahi-machi, Abeno-ku, \\ Osaka 545-8585, Japan
}


psychological, and social aspects of an individual. QOL has been reported to affect the prognosis of many types of cancer, and several studies used various QOL assessment tools to determine the relationship between QOL and cancer prognosis (Dancey et al. 1997; Giesinger et al. 2016; Gotay et al. 2008; Kaasa et al. 1989; Maisey et al. 2002). Healthrelated (HR)-QOL has been set as a secondary endpoint in various clinical trials (Aihara et al. 2014; Howell et al. 2015; Ohsumi et al. 2011; Shiroiwa et al. 2011; Watanabe et al. 2009). Furthermore, HR-QOL has also been considered in the approval of new drugs by the US Food and Drug Administration. Although various QOL measures are available and many of them can adequately evaluate each aspect, some factors overlap and may not be applicable for certain situations. In Japan, the Quality of Life Questionnaire for Cancer Patients Treated with Anti-Cancer Drugs-Breast (QOL-ACD-B) suitable for the Japanese population as a disease-specific scale is often used for patients with breast cancer (Kurihara et al. 1999; Otsuka et al. 2015).

However, because it is a scale for advanced breast cancer, some items were difficult to evaluate in patients administered with preoperative chemotherapy (POC). Therefore, QOL-ACD-B was modified to be suitable for POC and was named the Quality of Life Questionnaire for Cancer Patients Treated with Anti-Cancer Drugs-Breast-Preoperative Chemotherapy (QOL-ACD-BP). In this study, we examined the usefulness of QOL-ACD-BP in patients with breast cancer administered with POC.

\section{Methods}

\section{Patients' background}

Regarding patients' characteristics, we targeted the same patients as previously reported (Asano et al. 2016; Goto et al. 2017). A total of 300 patients were treated with POC after being diagnosed with breast cancer between February 2007 and December 2016 at the Osaka City University Hospital. All cases were diagnosed with breast cancer via pathological examination using core-needle biopsy or vacuumassisted biopsy. In this study, cancer stage and therapeutic effect were evaluated via ultrasonography (US), computed tomography (CT), and bone scintigraphy. Breast cancer was classified into subtypes according to the immunohistochemical evaluation of oestrogen (ER), progesterone (PgR), human epidermal growth factor receptor 2 (HER2), and Ki67.

Breast cancer was categorised into the following immunophenotypes: luminal A $\left(\mathrm{ER}^{+}\right.$and/or $\mathrm{PgR}^{+}$, HER2 ${ }^{-}$, $\left.\mathrm{Ki} 67^{\text {low }}\right)$; luminal B $\left(\mathrm{ER}^{+}\right.$and/or $\left.\mathrm{PgR}^{+}, \mathrm{HER}^{+}\right)\left(\mathrm{ER}^{+}\right.$ and/or PgR $\left.{ }^{+}, \mathrm{HER}^{-}{ }^{-}, \mathrm{Ki}^{+} 7^{\text {high }}\right)$; HER2-enriched breast cancer (HER2BC; $\mathrm{ER}^{-}, \mathrm{PgR}^{-}$, and $\mathrm{HER}_{2}^{+}$); and triplenegative breast cancer (TNBC; $\mathrm{ER}^{-}, \mathrm{PgR}^{-}$, and $\mathrm{HER} 2^{-}$).
The cutoff of Ki-67 was set at $14 \%$ based on the previous report (Cheang et al. 2009). Luminal A and luminal B types were defined as hormone receptor-positive breast cancer (HRBC) (Goldhirsch et al. 2011). All patients received a standardised protocol of POC consisting of four courses of FEC100 $\left(500 \mathrm{mg} / \mathrm{m}^{2}\right.$ fluorouracil, $100 \mathrm{mg} / \mathrm{m}^{2}$ epirubicin, and $500 \mathrm{mg} / \mathrm{m}^{2}$ cyclophosphamide) every 3 weeks, followed by 12 courses of $80 \mathrm{mg} / \mathrm{m}^{2}$ paclitaxel administered weekly. The patients with HER2BC were additionally administered weekly $(2 \mathrm{mg} / \mathrm{kg})$ or tri-weekly $(6 \mathrm{mg} / \mathrm{kg})$ trastuzumab during paclitaxel treatment (Kawajiri et al. 2012; Mauri et al. 2005; Mieog et al. 2007). All patients received POC in the outpatient department. Therapeutic anti-tumour effects were evaluated according to the Response Evaluation Criteria in Solid Tumors guideline (Eisenhauer et al. 2009). We defined clinical partial response and complete response as 'responders' in the objective response rate (ORR), while clinical stable disease and clinical progressive disease were evaluated as 'non-responders'. Patients underwent surgery (i.e., total mastectomy or breast-conserving surgery) after POC (Kashiwagi et al. 2015). The pathological therapeutic effect of POC was evaluated using resected specimens, and a pathological complete response (pCR) was defined as the complete disappearance of the invasive components of the lesion with or without intraductal components (including that in the lymph nodes) according to the National Surgical Adjuvant Breast and Bowel Project B-18 protocol (Wolmark et al. 2001). All patients with breast-conserving surgery received postoperative radiotherapy to the remnant breast.

The standard postoperative adjuvant treatment was performed according to the breast cancer subtype. Disease-free survival (DFS) was defined as the period between the time of surgery and recurrence. Meanwhile, overall survival (OS) was defined as the time between surgery and death, and follow-up time was defined as the time between surgery and the time that the patient was last examined (death or last visit). Follow-up physical examination was performed every 3 months, US every 6 months, and CT and bone scintigraphy annually. The median follow-up period was 1477 days (range 63-3524 days) from the day of surgery.

\section{Scoring of QOL-ACD-BP}

QOL-ACD was developed by Kurihara and was supported by the Japanese Ministry of Health and Welfare (Kurihara et al. 1999). As it covers all cancers, QOL-ACD-B as a breast cancer disease-specific scale is available (Otsuka et al. 2015) (Supplementary Table 1).

We first evaluated QOL before and after POC using QOLACD-B. Before POC, the high QOL group was significantly associated with higher survival rates, both in terms of DFS and OS (date not shown). However, there was no significant difference in DFS or OS due to a QOL difference after POC 
(date not shown). It was thought that QOL greatly decreased due to symptoms of breast cancer itself, and the progression of breast cancer influenced prognosis. However, we noticed several problems. Because the subjects for QOL-ACD-B are those with advanced breast cancer, any items did not apply to the patients who received POC. On the other hand, few items for side effects and psychological and social aspects were available in QOL-ACD-B. Therefore, we modified a new QOL score to be appropriate for patients administered with POC and named it QOL-ACD-BP in this study. Briefly, QOL-ACD-BP consists of 18 items, each of which is classified into three subscales comprising 6 items, namely, 'physical aspects', 'emotional aspects', and social aspects' (Table 1). Other points are the same as QOL-ACD-B, and each item is scored from 1 to 5 , with 1 being the worst and 5 being the best. The score of the whole QOL and each subscale was the average of the items that could be evaluated.

\section{Evaluation of QOL-ACD-BP}

QOL before POC was retrospectively evaluated using QOL-ACD-BP. Patients receiving chemotherapy, not only for breast cancer but for various cancers, had responded to some questionnaires of medical persons such as nurses and pharmacists. First, in evaluating each item of QOLACD-BP, the same items as the other questionnaires were used as they were. Regarding the evaluation of items that did not have the same question in the other questionnaires, if detailed records of remarks on the items remained, they were evaluated using the records. Items that were difficult to evaluate were treated as no answer. Likewise, QOL at preoperative after POC was also evaluated. The change in QOL before and after POC was also calculated. The cut-off value of each QOL was determined using receiver operating characteristic curve analysis to stratify patients at high risk of malignancy-related recurrences. The median QOL before POC was 4.357 (range 3.071-4.714), and the cut-off value was 4.286 [AUC $0.630, p=0.002,95 \%$ confidence interval (CI) $0.549-0.710$, sensitivity $=82.4 \%$, specificity $=41.9 \%]$ (Fig. 1a). Similarly, the median QOL after POC was 3.964 (range 2.214-4.643), and the cut-off value was 3.714 (AUC $0.673, p<0.001,95 \%$ CI $0.595-0.751$, sensitivity $=81.1 \%$, specificity $=43.6 \%$ ) (Fig. 1b). Finally, the median change in QOL before and after POC was 0.643 (range - 1.143 to 1.500 ), and the cut-off value was 0.214 (AUC 0.614, $p=0.006,95 \%$ CI $0.534-0.693$, sensitivity $=87.8 \%$, specificity $=29.0 \%$ ) (Fig. 1c). Prognosis prediction and factor analysis were performed therefrom.

\section{Ethics}

This study was carried out at the Osaka City University Graduate School of Medicine, Osaka, Japan, according to the REporting recommendations for Tumor MARKer prognostic studies (REMARK) guidelines and a retrospectively written research, pathological evaluation, and statistical plan

Table 1 Quality of life questionnaire for cancer patients treated with anti-cancer drugs-Breast-preoperative chemotherapy (QOL-ACD-BP)

Physical aspects

1. Did you care about pain or numbness caused by disease or treatment?

2. Did you care about swelling caused by disease or treatment?

3. Did you care about the skin symptoms (redness, swelling, hotness, itching, hair loss, etc.) caused by disease or treatment?

4. Did you care about the dietary symptoms (food amount decreased, taste changed, body weight changed, etc.)?

5. Did you feel disturbing, tired, or insomnia?

6. Did you have any other concerns in your body (headache, breathlessness, palpitations, eye irritation, etc)?

Emotional aspects

7.

8.

9.

10 .

11.

12.

Social aspects

13.

14.

15.

16.

17

18.

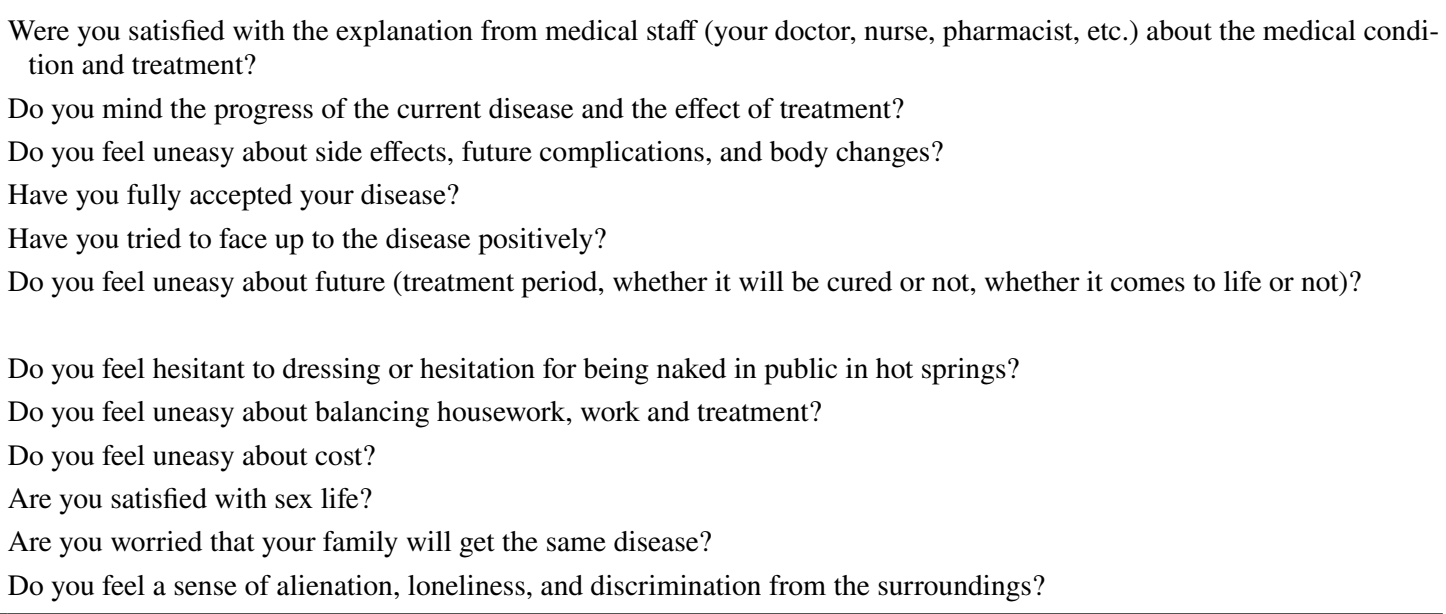




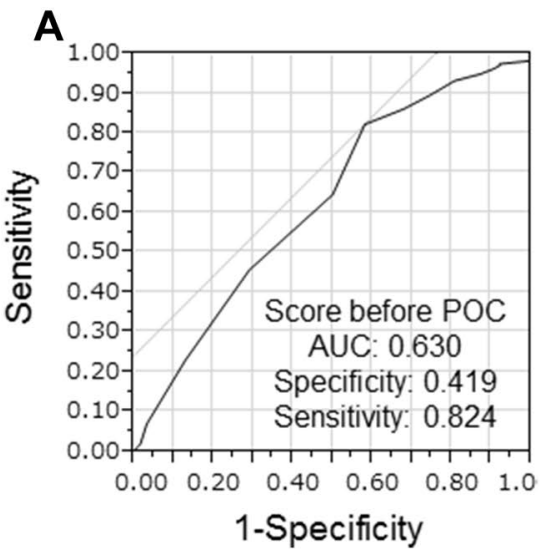

Fig. 1 Receiver operating characteristic (ROC) analysis. The median QOL before POC was 4.357 (range 3.071-4.714), and the cut-off value was 4.286 (AUC $0.630, p=0.002$, 95\% CI $0.549-0.710$, sensitivity $=82.4 \%$, specificity $=41.9 \%)($ a). Similarly, the median QOL after POC was 3.964 (range 2.214-4.643), and the cut-off value

(McShane et al. 2005). This study was performed in accordance with the provisions of the Declaration of Helsinki (64th WMA General Assembly, Fortaleza, Brazil, October 2013). Written informed consent was obtained from all patients. The Osaka City University Ethics Committee approved the study protocol (Approval number: 926).

\section{Statistical analysis}

All statistical analyses were conducted using the JMP software package (SAS, Tokyo, Japan). The relationship between each factor was examined using chi-squared test. The Kaplan-Meier method and the log-rank test were used for comparison between DFS and OS. The hazard ratios and 95\% CIs were calculated using the Cox proportional hazards model. Univariate and multivariate analyses were performed using the Cox regression model. A $p$ value of $<0.05$ was considered to indicate statistical significance.

\section{Results}

\section{Correlations between clinicopathological features and QOL-ACD-BP}

The clinicopathological features of the 300 patients were the same as that previously reported. The details are listed in Table 2 . The median age at surgery was 55 years (range 27-90 years), and the median tumour diameter was $29.0 \mathrm{~mm}$ (range $10.2-98.1 \mathrm{~mm}$ ). Thirty-eight $(12.7 \%$ ) patients had skin infiltration, and $230(70.0 \%)$ were diagnosed with lymph node metastasis at the time of breast cancer diagnosis. A total of 149 (49.7\%), 57 (19.0\%), and 94 (31.3\%) patients was 3.714 (AUC $0.673, p<0.001$, 95\% CI $0.595-0.751$, sensitivity $=81.1 \%$, specificity $=43.6 \%)(b)$. Finally, the median change in QOL before and after POC was 0.643 (range $-1.143-1.500$ ), and the cut-off value was 0.214 (AUC $0.614, p=0.006,95 \%$ CI $0.534-0.693$, sensitivity $=87.8 \%$, specificity $=29.0 \%)(\mathbf{c})$

were diagnosed with HRBC, HERBC, and TNBC, respectively. The rate of responders for POC from the study cohort was $89.3 \%$, with 99 patients (33.0\%) achieving pCR. After surgery, 62 (20.7\%) patients had recurrence, and $30(10.0 \%)$ died from breast cancer. Based on the cut-off value described in the 'Methods' section, $185(61.7 \%)$ were classified as the high QOL group and 115 (38.3\%) as the low QOL group before POC. Similarly, after POC, 228 (76.0\%) patients were classified as the high QOL group and $72(24.0 \%)$ as the low QOL group. Finally, in terms of the change in QOL score before and after POC, 47 (15.7\%) patients were classified into the low group, that is, the group in which the QOL was significantly decreased by POC. Hereafter, it is called the 'lower change group'. Meanwhile, 253 (84.3\%) patients were classified into the high group, that is, the group which POC did not significantly decrease the QOL, and this group is called the 'higher change group'.

Correlations between the clinicopathological feature and each QOL group are listed in Table 3. Before POC, the tumor size was larger in the low QOL group than that in the high QOL group $(p<0.001)$. Further, in the low QOL group, the rate of skin infiltration and PgR positivity was higher than that in the high QOL group $(p<0.001, p=0.029$, respectively). After POC, the tumour size was significantly larger and the rate of 'responder' was lower in the low QOL group than the high QOL group $(p=0.042, p=0.020$, respectively). In the 'higher change group', the rate of ER positivity was significantly higher compared to the 'lower change group' ( $p=0.014)$. Moreover, in HRBC, the decrease of QOL by POC was significantly small, while QOL in the TNBC group was significantly decreased $(p=0.008$, $p=0.001$, respectively). It also correlated with ORR, and QOL significantly decreased in the non-responders of ORR 
Table 2 Clinicopathological features of 300 patients who were treated with preoperative chemotherapy

\begin{tabular}{|c|c|}
\hline Parameters $(n=300)$ & Number of patients (\%) \\
\hline \multicolumn{2}{|l|}{ Age (years old) } \\
\hline$\leq 35 / 36-55 / 56-70 / 71 \leq$ & $36(12.0 \%) / 120(40.0 \%) / 127(42.3 \%) / 17(5.7 \%)$ \\
\hline \multicolumn{2}{|l|}{ Tumor size (mm) } \\
\hline$\leq 20 / 20<, \leq 50 / 50 \leq$ & $35(11.7 \%) / 224(74.7 \%) / 41(13.7 \%)$ \\
\hline \multicolumn{2}{|l|}{ Skin infiltration } \\
\hline Negative/positive & $262(87.3 \%) / 38(12.7 \%)$ \\
\hline \multicolumn{2}{|l|}{ Lymph node metastasis } \\
\hline $\mathrm{N} 0 / \mathrm{N} 1 / \mathrm{N} 2 / \mathrm{N} 3$ & $90(30.0 \%) / 116(38.6 \%) / 65(21.7 \%) / 29(9.7 \%)$ \\
\hline \multicolumn{2}{|l|}{ Estrogen receptor } \\
\hline Negative/positive & $155(51.7 \%) / 145(48.3 \%)$ \\
\hline \multicolumn{2}{|l|}{ Progesterone receptor } \\
\hline Negative/positive & $200(66.7 \%) / 100(33.3 \%)$ \\
\hline \multicolumn{2}{|l|}{ HER2 } \\
\hline Negative/positive & $212(70.7 \%) / 88(29.3 \%)$ \\
\hline \multicolumn{2}{|l|}{ Ki67 } \\
\hline Low/high & $96(32.0 \%) / 204(68.0 \%)$ \\
\hline \multicolumn{2}{|l|}{ Intrinsic subtype } \\
\hline HRBC/HER2BC/TNBC & $149(49.7 \%) / 57(19.0 \%) / 94(31.3 \%)$ \\
\hline \multicolumn{2}{|l|}{ ORR } \\
\hline Non-responders/responders & $32(10.7 \%) / 268(89.3 \%)$ \\
\hline \multicolumn{2}{|l|}{$\mathrm{pCR}$} \\
\hline Negative/positive & $201(67.0 \%) / 99(33.0 \%)$ \\
\hline \multicolumn{2}{|l|}{ Reccurence } \\
\hline Negative/positive & $238(79.3 \%) / 62(20.7 \%)$ \\
\hline \multicolumn{2}{|l|}{ Death from breast cancer } \\
\hline Negative/positive & $270(90.0 \%) / 30(10.0 \%)$ \\
\hline \multicolumn{2}{|c|}{ QOL-ACD-BP before neoadjuvant chemotherapy } \\
\hline Low/high & $115(38.3 \%) / 185(61.7 \%)$ \\
\hline \multicolumn{2}{|c|}{ Change of QOL from before POC to after POC } \\
\hline The lower change/the higher change & $47(15.7 \%) / 253(84.3 \%)$ \\
\hline \multicolumn{2}{|c|}{ QOL-ACD-BP after neoadjuvant chemotherapy } \\
\hline Low/high & $72(24.0 \%) / 228(76.0 \%)$ \\
\hline
\end{tabular}

$H E R$ human epidermal growth factor receptor, $H R B C$ hormone receptor-positive breast cancer (ER ${ }^{+}$and/ or $\mathrm{PgR}+), H E R 2 B C$ human epidermal growth factor receptor 2-enriched breast cancer $\left(\mathrm{ER}^{-}, \mathrm{PgR}^{-}\right.$, and HER2+), TNBC triple negative breast cancer $\left(\mathrm{ER}^{-}, \mathrm{PgR}^{-}\right.$, and HER2 $\left.{ }^{-}\right), O R R$ objective response rate, $p C R$ pathological complete response, $Q O L-A C D-B P$ Quality of Life Questionnaire for Cancer Patients Treated with Anti-Cancer Drugs-Breast-Preoperative Chemotherapy $(p=0.040)$. No correlation between QOL before and after POC was noted $(p=0.319)$. However, QOL significantly decreased in the high QOL before POC, and the number of patients in the 'lower change group' being classified into the low QOL group after POC was higher $(p<0.001, p<0.001$, respectively).

\section{Correlation between each QOL and prognosis}

Before POC, the high QOL group was significantly associated with higher survival rates, both in terms of DFS $(p=0.010, \log$-lank) and OS ( $p=0.039$, log-lank) (Fig. 2a, b). Despite the lack of correlation between QOL before and after POC, the high QOL group was significantly associated with higher survival rates even after POC (DFS: $p<0.001$, log-rank. OS: $p=0.001, \log$-rank) (Fig. 2c, d). Furthermore, the 'higher change group' was significantly associated with higher survival rates than the 'lower change group' (DFS: $p<0.001$, log-rank. OS: $p=0.038, \log$-rank) (Fig. 2e, f). In the univariate analysis with DFS, the high QOL group either before or after POC and the 'higher change group' were found to significantly contribute to a longer DFS (before POC: $p=0.012$, HR 0.522; after POC: $p<0.001$, HR 0.941; change of QOL: $p=0.001$, HR 0.380). However, in the multivariate analysis, lymph node status $(p=0.003$, HR 2.816) and response to NAC $(p<0.001$, HR 0.275$)$ were 


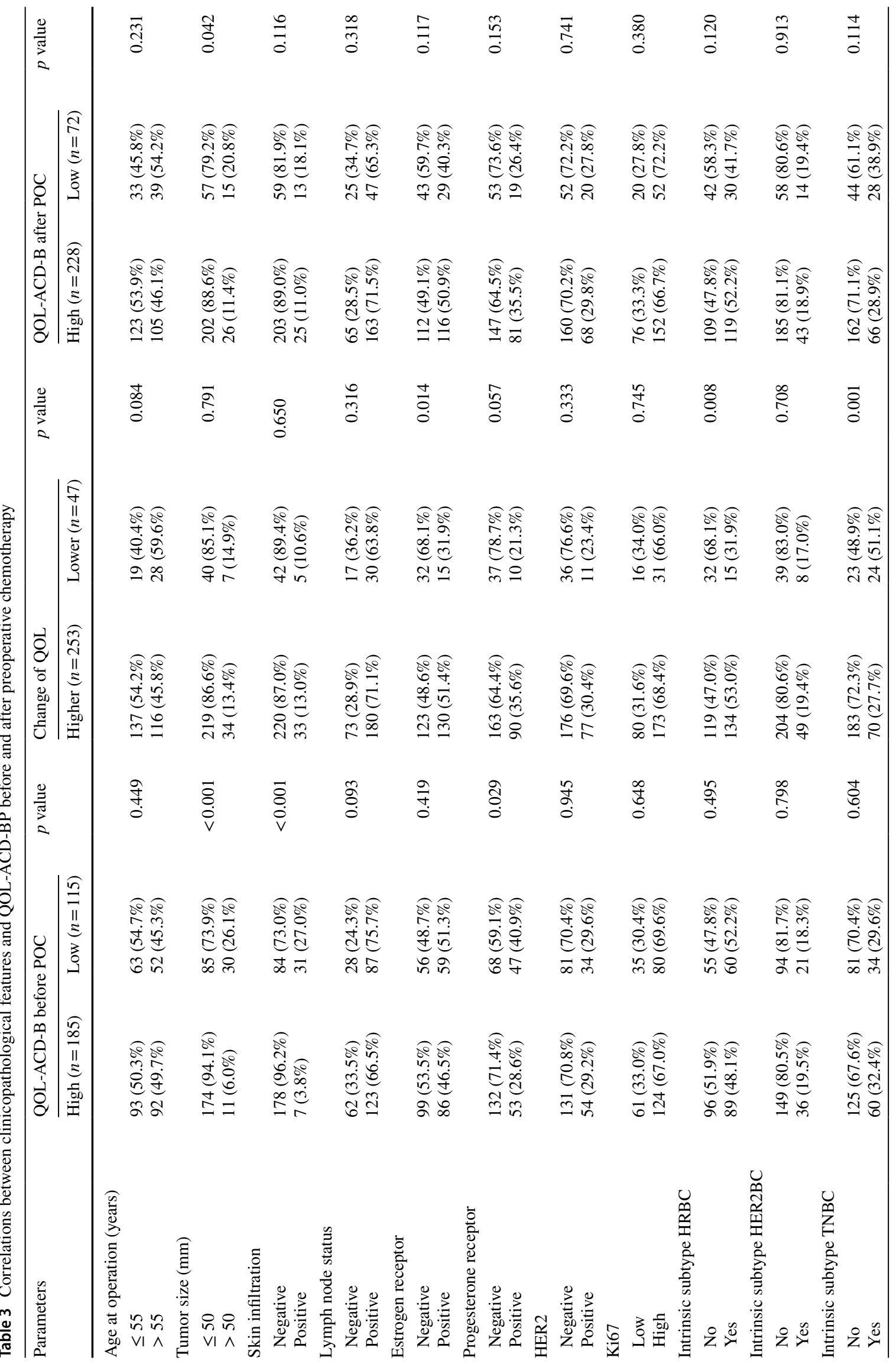




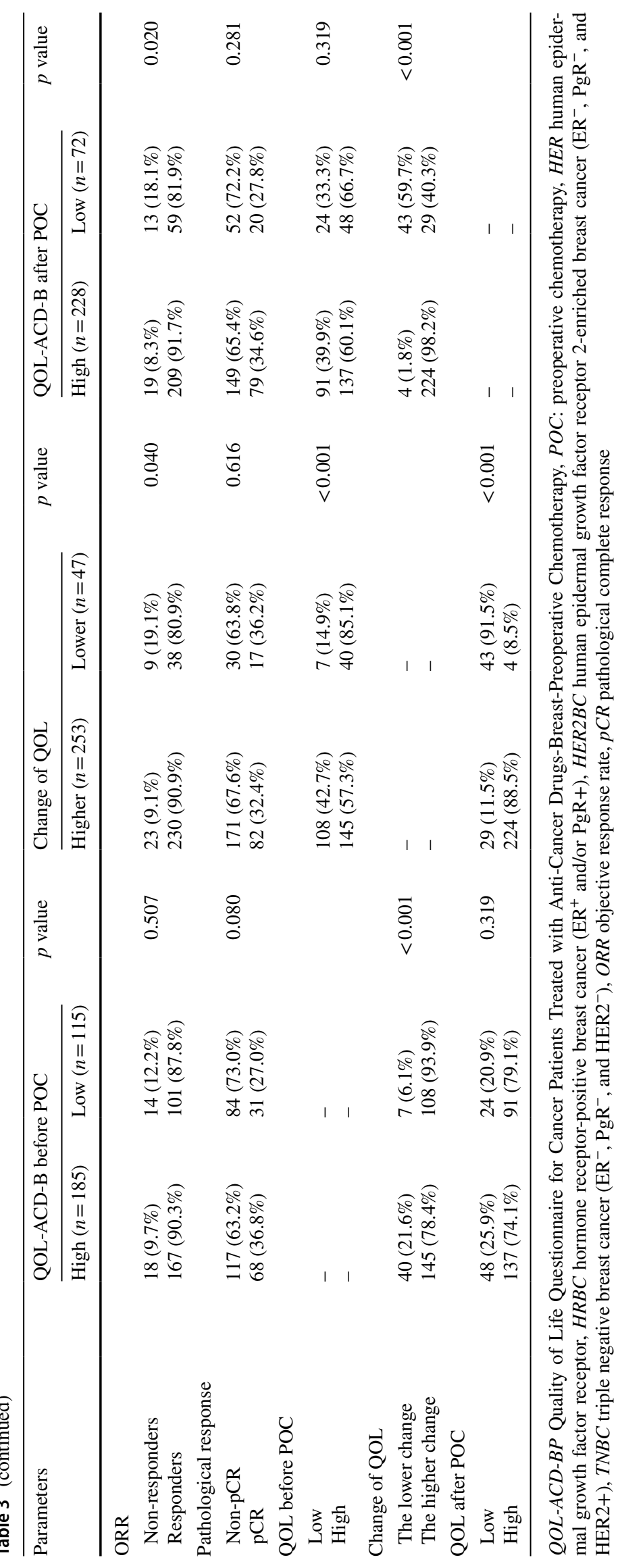


A

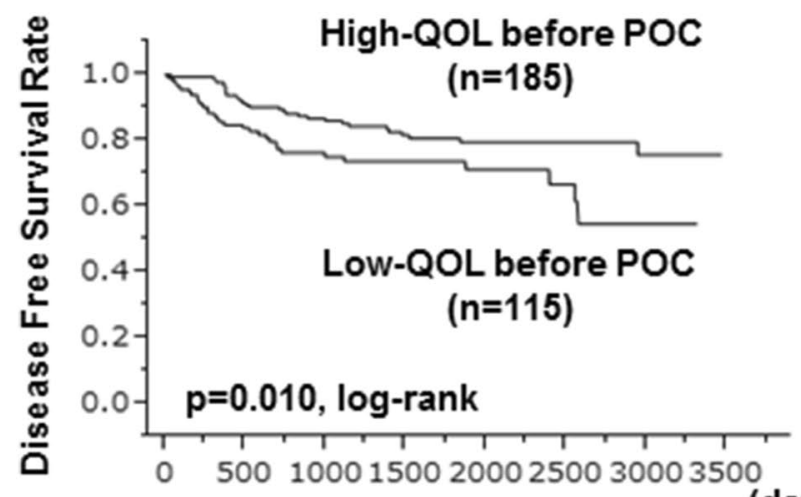

No. at risk

Days After Operation

$\begin{array}{rrrrrrrr}185 & 152 & 115 & 83 & 61 & 37 & 18 & 0 \\ 115 & 85 & 58 & 45 & 27 & 14 & 3 & 0\end{array}$

C

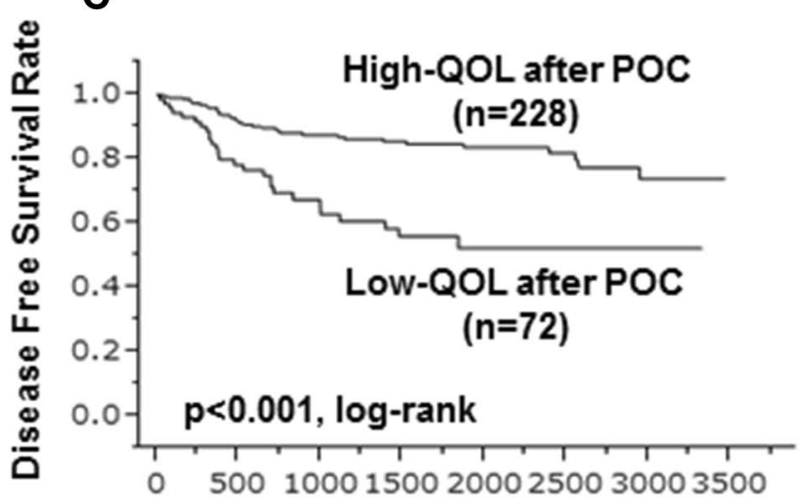

No. at risk

Days After Operation

(days)

$\begin{array}{rrrrrrrr}228 & 189 & 145 & 106 & 75 & 43 & 19 & 0 \\ 72 & 48 & 28 & 22 & 13 & 8 & 2 & 0\end{array}$

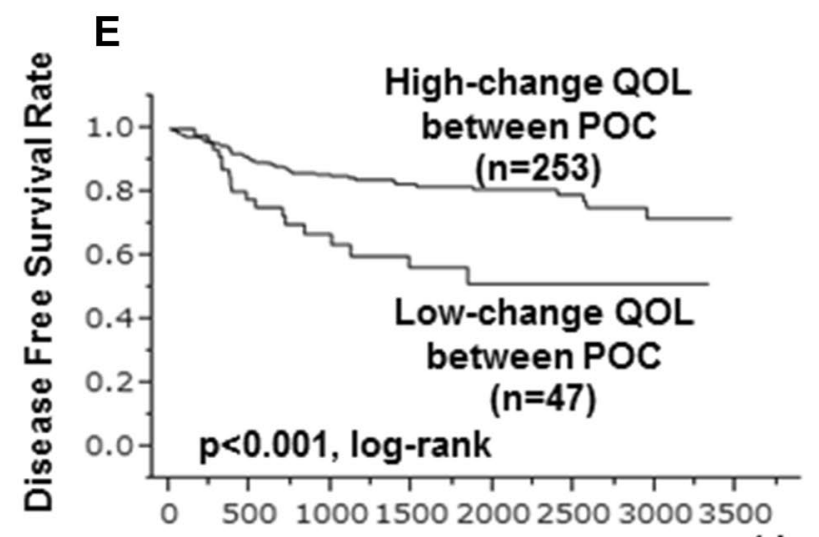

Days After Operation

(days)

No. at risk

$\begin{array}{rrrrrrrr}253 & 205 & 154 & 115 & 79 & 46 & 19 & 0 \\ 47 & 32 & 19 & 17 & 9 & 5 & 2 & 0\end{array}$

\section{B}

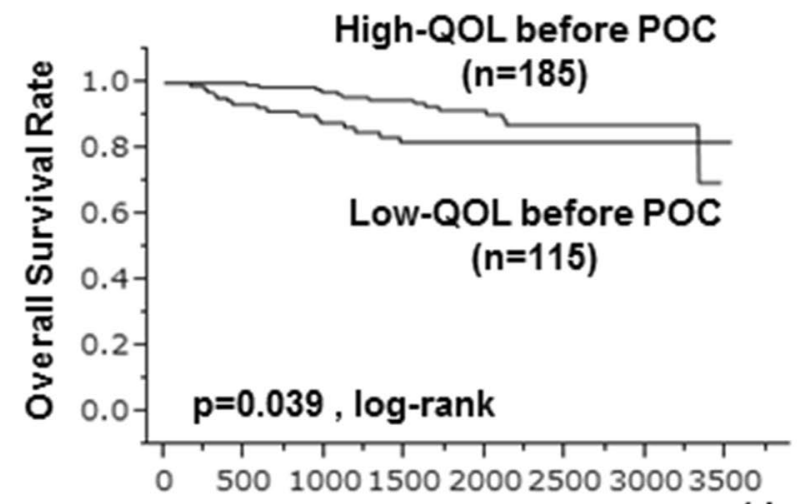

No. at risk

Days After Operation

(days)

D

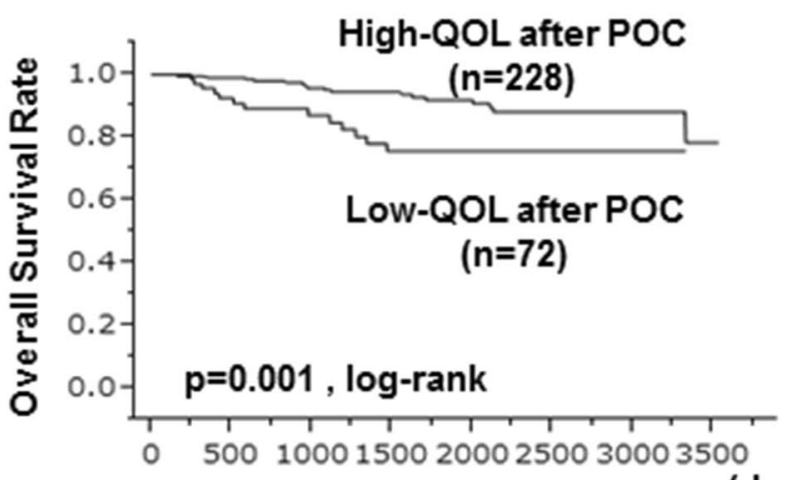

No. at risk

$\begin{array}{rrrrrrrr}185 & 166 & 131 & 98 & 68 & 40 & 20 & 0 \\ 115 & 94 & 70 & 50 & 31 & 16 & 7 & 1\end{array}$

D

Days After Operation

(days)

F

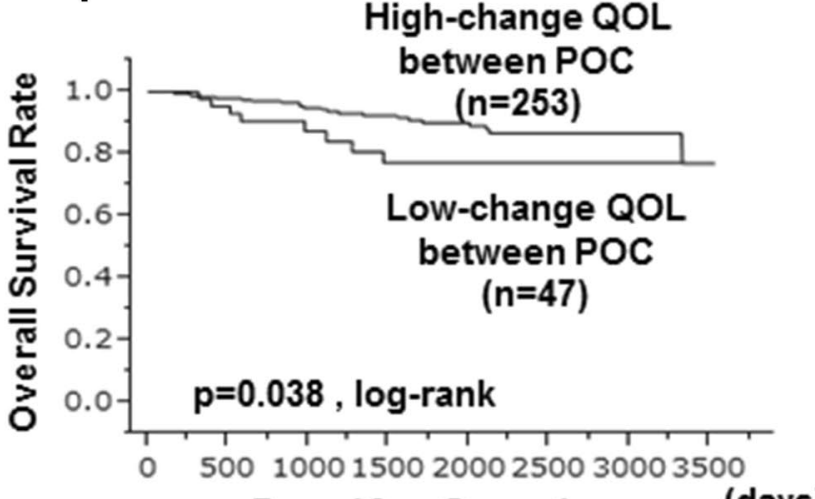

No. at risk

$$
\text { Days After Operation }
$$

(days)

$\begin{array}{rrrrrrrr}253 & 221 & 174 & 129 & 86 & 50 & 24 & 1 \\ 47 & 39 & 27 & 19 & 13 & 6 & 3 & 0\end{array}$


४Fig. 2 In comparison of disease free survival (DFS) and overall survival (OS) between the high QOL group and the low QOL group before preoperative chemotherapy (POC) the high QOL group was significantly associated with higher survival rates, both in terms of DFS ( $p=0.010$, log-lank) (a) and OS ( $p=0.039$, log-lank) (b). After POC the high QOL group was significantly associated with higher survival rates, both in terms of DFS $(p<0.001, \log$-lank) (c) and OS ( $p=0.001, \log$-lank) (d). The higher change group and the lower change group of QOL before and after POC the higher QOL group was significantly associated with higher survival rates, both in terms of DFS ( $p<0.001, \log$-lank) (e) and OS ( $p=0.038, \log$-lank) (f)

independent factors, whereas none of the QOL was an independent factor (Table 4). On the other hand, in the univariate analysis of OS, the high QOL either before or after POC was found to significantly contribute to a longer OS (before POC: $p=0.045$, HR 0.478; after POC: $p=0.004$, HR 0.321). High QOL before or after POC was also an independent factor in the multivariate analysis (before POC: $p=0.048$, HR 0.441; after POC: $p=0.030$, HR 0.273) (Table 5).

\section{Discussion}

Recently, maintaining QOL in cancer treatment has become important, and QOL is often evaluated as a secondary endpoint in the clinical research of various treatments. QOL has been evaluated using various assessment tools such as the European Organization for Research and Treatment of Cancer Quality of Life Questionnaire-Core 30, Functional Assessment of Cancer Therapy, and Cancer Rehabilitation Evaluation System (CARES) (Aaronson et al. 1993; Cella et al. 1993; Schouten et al. 2016, 2017). Items are comprehensively set so that they can be evaluated according to any carcinoma. As such, questions are diversified, and some items that are not applicable depending on the carcinoma or degree of progression to be investigated are included. In the case of patients with breast cancer, distress and anxiety due to the malignancy are inevitable. A study reported that no significant difference was observed in $63 \%$ of clinical trials that used QOL as a secondary endpoint, and the importance of establishing a clear hypotheses and setting subjective items to be investigated before QOL researched has been established (Bottomley and Therasse 2002). Because we measured QOL before and after POC, we determined that QOL-ACD-B is not suitable and changed part of it to be a breast cancer-specific QOL scale in Japan (Kurihara et al. 1999; Otsuka et al. 2015). Herein, we established a new QOL scale and confirmed its practicality.

Before POC, the frequency of skin infiltration and lymph node metastasis was higher (but insignificant) and the tumour size was larger in the low QOL group. This means that QOL before POC is influenced by the degree of disease progression at diagnosis. In advanced breast cancer,
QOL decreased because of physical symptoms. Therefore, in the low QOL group, DFS and OS are significantly shorter. Early stage cancer without tumour-related symptoms has been reported to generally have less influence on prognosis (Gotay et al. 2008), and this supports the results of the current study. The appearance of symptoms is hypothesised to decreased that the overall QOL.

The side effect of POC substantially reduces QOL. However, in patients with tumour-related symptoms, their symptoms disappear due to POC; thus, their decline in QOL is limited. Furthermore, the QOL of patients who can be treated with POC is not significantly impaired, and the difference between the maximum and minimum before POC is small. As such, the QOL of patients in the high QOL group before POC significantly decreased and the change of QOL was correlated with QOL after POC.

QOL after POC correlated with ORR of POC. This result can be attributed to the disappearance of tumour-related symptoms via POC and the improvement of the emotional aspect due to the effect of POC. QOL after POC correlating with tumour size suggests that the larger the primary tumour, the better the treatment effect perceived by the patient and improvement in QOL. The correlation between change of QOL and ORR supports this theory. Correlations with QOL, particularly change of QOL, and hormone receptors were particularly observed. The options for drug therapy vary significantly between HRBC and TNBC; thus, the difference in change of QOL will vary according to the choice of treatment. However, only one regimen of anticancer drugs was used in this study, which may be due to the insignificant differences in clinical factors of some subtypes.

QOL and changes in QOL after treatment were reported to be significant predictors of subsequent survival (Coates et al. 1992; Shimozuma et al. 2000). In addition, some studies reported that pain and decreased appetite are poor prognostic factors (Kramer et al. 2000; Lee et al. 2010; Luoma et al. 2003; Spiegel et al. 1989). In this study, no symptom was a prognostic factor. However, overall worsening of the physical symptoms is correlated with the decrease of the overall QOL, and a similar result was reported (Charalambous et al. 2017). Previous studies targeted patients with advanced cancer with distant metastasis, and the correlation between QOL and performance status (PS) has been studied. If QOL and PS decrease, there is little possibility that they will improve thereafter, and treatment options will be reduced, and prognosis will be affected. However, in the current study, because QOL decreased with POC, we believe that the physical symptoms due to the side effects have improved after POC and surgery. However, the temporary decline in QOL affects the patient's prognosis and options for future treatment.

This research has some limitations such as the limited accuracy of evaluation because the QOL was scored 
Table 4 Univariate and multivariate analysis with respect to DFS in 300 cases who were treated with preoperative chemotherapy

\begin{tabular}{|c|c|c|c|c|c|c|}
\hline \multirow[t]{2}{*}{ Parameters } & \multicolumn{3}{|c|}{ Univarite analysis } & \multicolumn{3}{|c|}{ Multivariate analysis } \\
\hline & Hazard ratio & $95 \% \mathrm{CI}$ & $p$ value & Hazard ratio & $95 \% \mathrm{CI}$ & $p$ value \\
\hline \multicolumn{7}{|c|}{ Age at operation (years) } \\
\hline $\begin{array}{l}\leq 55 \\
>55\end{array}$ & 0.693 & $0.414-1.143$ & 0.151 & & & \\
\hline \multicolumn{7}{|l|}{ Tumor size (mm) } \\
\hline $\begin{array}{l}\leq 50 \\
>50\end{array}$ & 2.882 & $1.602-4.948$ & 0.001 & 1.730 & $0.867-3.299$ & 0.117 \\
\hline \multicolumn{7}{|l|}{ Skin infiltration } \\
\hline $\begin{array}{l}\text { Negative } \\
\text { Positive }\end{array}$ & 2.034 & $1.056-3.646$ & 0.035 & 1.162 & $0.530-2.425$ & 0.700 \\
\hline \multicolumn{7}{|l|}{ Lymph node status } \\
\hline $\begin{array}{l}\text { Negative } \\
\text { Positive }\end{array}$ & 2.426 & $1.259-5.268$ & 0.007 & 2.816 & $1.398-6.315$ & 0.003 \\
\hline \multicolumn{7}{|l|}{ Estrogen receptor } \\
\hline $\begin{array}{l}\text { Negative } \\
\text { Positive }\end{array}$ & 0.751 & $0.451-1.238$ & 0.262 & & & \\
\hline \multicolumn{7}{|c|}{ Progesterone receptor } \\
\hline $\begin{array}{l}\text { Negative } \\
\text { Positive }\end{array}$ & 0.928 & $0.539-1.553$ & 0.781 & & & \\
\hline \multicolumn{7}{|l|}{ HER2 } \\
\hline \multicolumn{7}{|l|}{ Positive } \\
\hline \multicolumn{7}{|l|}{ Ki67 } \\
\hline \multicolumn{7}{|l|}{ High } \\
\hline \multicolumn{7}{|c|}{ Intrinsic subtype HRBC } \\
\hline $\begin{array}{l}\text { No } \\
\text { Yes }\end{array}$ & 0.757 & $0.456-1.27$ & 0.274 & & & \\
\hline \multicolumn{7}{|c|}{ Intrinsic subtype HER2BC } \\
\hline $\begin{array}{l}\text { No } \\
\text { Yes }\end{array}$ & 0.836 & $0.400-1.574$ & 0.597 & & & \\
\hline \multicolumn{7}{|c|}{ Intrinsic subtype TNBC } \\
\hline $\begin{array}{l}\text { No } \\
\text { Yes }\end{array}$ & 1.532 & $0.907-2.539$ & 0.109 & & & \\
\hline ORR & & & & & & \\
\hline $\begin{array}{l}\text { Non-responders } \\
\text { Responders }\end{array}$ & 0.265 & $0.151-0.492$ & $<0.001$ & 0.275 & $0.146-0.540$ & $<0.001$ \\
\hline Pathological respo & & & & & & \\
\hline $\begin{array}{l}\text { Non-pCR } \\
\text { pCR }\end{array}$ & 0.438 & $0.222-0.795$ & 0.006 & 0.578 & $0.284-1.099$ & 0.097 \\
\hline QOL-ACD-BP be & $\mathrm{POC}$ & & & & & \\
\hline $\begin{array}{l}\text { Low } \\
\text { High }\end{array}$ & 0.522 & $0.316-0.863$ & 0.012 & 0.571 & $0.319-1.036$ & 0.065 \\
\hline Change of QOL be & en POC & & & & & \\
\hline $\begin{array}{l}\text { Lower change } \\
\text { Higher change }\end{array}$ & 0.380 & $0.223-0.675$ & 0.001 & 0.557 & $0.243-1.222$ & 0.146 \\
\hline QOL-ACD-BP aft & & & & & & \\
\hline $\begin{array}{l}\text { Low } \\
\text { High }\end{array}$ & 0.941 & $0.923-0.962$ & $<0.001$ & 0.469 & $0.234-1.011$ & 0.053 \\
\hline
\end{tabular}

$D F S$ disease-free survival, $P O C$ preoperative chemotherapy, $C I$ confidence intervals, HER human epidermal growth factor receptor, $H R B C$ hormone receptor-positive breast cancer (ER + and/or PgR+), HER2BC human epidermal growth factor receptor 2-enriched breast cancer ( $\mathrm{ER}^{-}, \mathrm{PgR}^{-}$, and HER2+), TNBC triple negative breast cancer $\left(\mathrm{ER}^{-}, \mathrm{PgR}^{-}\right.$, and $\left.\mathrm{HER} 2^{-}\right), O R R$ objective response rate, $p C R$ pathological complete response 
Table 5 Univariate and multivariate analysis with respect to OS in 300 cases who were treated with preoperative chemotherapy

\begin{tabular}{|c|c|c|c|c|c|c|}
\hline \multirow[t]{2}{*}{ Parameters } & \multicolumn{3}{|c|}{ Univarite analysis } & \multicolumn{3}{|c|}{ Multivariate analysis } \\
\hline & Hazard ratio & $95 \% \mathrm{CI}$ & $p$ value & Hazard ratio & $95 \% \mathrm{CI}$ & $p$ value \\
\hline \multicolumn{7}{|c|}{ Age at operation (years) } \\
\hline $\begin{array}{l}\leq 55 \\
>55\end{array}$ & 0.664 & $0.311-1.367$ & 0.268 & & & \\
\hline \multicolumn{7}{|l|}{ Tumor size (mm) } \\
\hline $\begin{array}{l}\leq 50 \\
>50\end{array}$ & 2.563 & $1.070-5.537$ & 0.036 & 1.318 & $0.484-3.341$ & 0.576 \\
\hline \multicolumn{7}{|l|}{ Skin infiltration } \\
\hline $\begin{array}{l}\text { Negative } \\
\text { Positive }\end{array}$ & 2.233 & $0.883-4.969$ & 0.086 & & & \\
\hline \multicolumn{7}{|l|}{ Lymph node status } \\
\hline $\begin{array}{l}\text { Negative } \\
\text { Positive }\end{array}$ & 3.299 & $1.164-13.822$ & 0.022 & 3.490 & $1.093-15.795$ & 0.034 \\
\hline \multicolumn{7}{|l|}{ Estrogen receptor } \\
\hline $\begin{array}{l}\text { Negative } \\
\text { Positive }\end{array}$ & 0.477 & $0.213-1.000$ & 0.050 & & & \\
\hline \multicolumn{7}{|c|}{ Progesterone receptor } \\
\hline $\begin{array}{l}\text { Negative } \\
\text { Positive }\end{array}$ & 0.881 & $0.394-1.843$ & 0.742 & & & \\
\hline \multicolumn{7}{|l|}{ HER2 } \\
\hline $\begin{array}{l}\text { Negative } \\
\text { Positive }\end{array}$ & 0.29 & $0.069-0.822$ & 0.017 & 0.472 & $0.105-1.566$ & 0.233 \\
\hline \multicolumn{7}{|l|}{ Ki67 } \\
\hline \multicolumn{7}{|l|}{ High } \\
\hline \multicolumn{7}{|c|}{ Intrinsic subtype HRBC } \\
\hline $\begin{array}{l}\text { No } \\
\text { Yes }\end{array}$ & 0.513 & $0.233-1.071$ & 0.076 & & & \\
\hline \multicolumn{7}{|c|}{ Intrinsic subtype HER2BC } \\
\hline \multicolumn{7}{|l|}{ Yes } \\
\hline \multicolumn{7}{|c|}{ Intrinsic subtype TNBC } \\
\hline \multicolumn{7}{|l|}{ Yes } \\
\hline \multicolumn{7}{|l|}{ ORR } \\
\hline $\begin{array}{l}\text { Non-responders } \\
\text { Responders }\end{array}$ & 0.227 & $0.103-0.548$ & 0.002 & 0.199 & $0.080-0.522$ & 0.002 \\
\hline \multicolumn{7}{|c|}{ Pathological response } \\
\hline $\begin{array}{l}\text { Non-pCR } \\
\text { pCR }\end{array}$ & 0.376 & $0.127-0.905$ & 0.028 & 0.441 & $0.142-1.146$ & 0.095 \\
\hline \multicolumn{7}{|c|}{ QOL-ACD-BP before POC } \\
\hline $\begin{array}{l}\text { Low } \\
\text { High }\end{array}$ & 0.478 & $0.230-0.982$ & 0.045 & 0.441 & $0.196-0.992$ & 0.048 \\
\hline \multicolumn{7}{|c|}{ Change of QOL between POC } \\
\hline $\begin{array}{l}\text { Lower change } \\
\text { Higher change }\end{array}$ & 0.432 & $0.199-1.039$ & 0.060 & 1.225 & $0.345-4.078$ & 0.744 \\
\hline \multicolumn{7}{|c|}{ QOL-ACD-B after POC } \\
\hline $\begin{array}{l}\text { Low } \\
\text { High }\end{array}$ & 0.321 & $0.154-0.678$ & 0.004 & 0.273 & $0.098-0.872$ & 0.030 \\
\hline
\end{tabular}

$O S$ overall survival, $P O C$ preoperative chemotherapy, $C I$ confidence intervals, HER human epidermal growth factor receptor, $H R B C$ hormone receptor-positive breast cancer $\left(\mathrm{ER}^{+}\right.$and/or $\left.\mathrm{PgR}+\right), H E R 2 B C$ human epidermal growth factor receptor 2-enriched breast cancer ( $\mathrm{ER}^{-}, \mathrm{PgR}^{-}$, and HER2+), TNBC triple negative breast cancer $\left(\mathrm{ER}^{-}, \mathrm{PgR}^{-}\right.$, and $\left.\mathrm{HER} 2^{-}\right), O R R$ objective response rate, $p C R$ pathological complete response 
retrospectively using chart records. Prospective studies using a QOL questionnaire are needed to confirm our results.

In conclusion, our study shows that QOL after POC may also affect prognosis and supported the importance of maintaining QOL in cancer treatment. In patients with breast cancer treated with POC, QOL-ACD-BP, which is a new QOL evaluation index, was found to be a useful tool for predicting the patients' prognosis.

Acknowledgements This study was supported in part by Grants-in Aid for Scientific Research (KAKENHI, nos. 25461992, 26461957, and $17 \mathrm{~K} 10559$ ) from the Ministry of Education, Science, Sports, Culture and Technology of Japan. We thank Yayoi Matsukiyo and Tomomi Okawa (Department of Surgical Oncology, Osaka City University Graduate School of Medicine) for helpful advice regarding data management.

Author contributions All authors were involved in the preparation of this manuscript. KTakada collected the data, and wrote the manuscript. SK, WG, YA, KTakahashi, TM and TT performed the operation and designed the study. K Takada, SK and ST summarized the data and revised the manuscript. $\mathrm{KH}$ and $\mathrm{MO}$ substantially contributed to the study design, performed the operation, and revised the manuscript. All authors read and approved the final manuscript.

Funding This study was funded by Grants from the Japan Society for the Promotion of Science (KAKENHI, nos. 25461992, 26461957, and 17K10559) to Shinichiro Kashiwagi.

\section{Compliance with ethical standards}

Conflict of interest All of authors have no conflicts of interest to disclose.

Ethical approval This study was conducted at the Osaka City University Graduate School of Medicine, Osaka, Japan, according to the Reporting Recommendations for Tumor Marker Prognostic Studies guidelines and following a retrospectively written research proposal, pathological evaluation, and statistical plan. This study conformed to the provisions of the Declaration of Helsinki. All patients were informed of the investigational nature of this study and provided their written informed consent. The Ethics Committee of Osaka City University approved the study protocol (\#926).

Informed consent Informed consent was obtained from all individual participants included in the study.

Open Access This article is distributed under the terms of the Creative Commons Attribution 4.0 International License (http://creativeco mmons.org/licenses/by/4.0/), which permits unrestricted use, distribution, and reproduction in any medium, provided you give appropriate credit to the original author(s) and the source, provide a link to the Creative Commons license, and indicate if changes were made.

\section{References}

Aaronson NK et al (1993) The European Organization for Research and Treatment of Cancer QLQ-C30: a quality-of-life instrument for use in international clinical trials in oncology. J Natl Cancer Inst 85:365-376

Aihara T et al (2014) Anastrozole versus tamoxifen as adjuvant therapy for Japanese postmenopausal patients with hormone-responsive breast cancer: efficacy results of long-term follow-up data from the N-SAS BC 03 trial Breast. Cancer Res Treat 148:337-343. https://doi.org/10.1007/s10549-014-3155-8

Asano Y et al (2016) Tumour-infiltrating CD8 to FOXP3 lymphocyte ratio in predicting treatment responses to neoadjuvant chemotherapy of aggressive breast cancer. Br J Surg 103:845-854. https://doi. org/10.1002/bjs. 10127

Bottomley A, Therasse P (2002) Quality of life in patients undergoing systemic therapy for advanced breast cancer. Lancet Oncol 3:620-628

Cella DF et al (1993) The Functional Assessment of Cancer Therapy scale: development and validation of the general measure. J Clin Oncol 11:570-579. https://doi.org/10.1200/JCO.1993.11.3.570

Charalambous A, Kaite CP, Charalambous M, Tistsi T, Kouta C (2017) The effects on anxiety and quality of life of breast cancer patients following completion of the first cycle of chemotherapy. SAGE Open Med 5:2050312117717507. https://doi.org/10.1177/20503 12117717507

Cheang MC, Chia SK, Voduc D, Gao D, Leung S, Snider J, Watson M, Davies S, Bernard PS, Parker JS et al (2009) Ki67 index, HER2 status, and prognosis of patients with luminal B breast cancer. J Natl Cancer Inst 101(10):736-750. https://doi.org/10.1093/jnci/djp082

Coates A, Gebski V, Signorini D, Murray P, McNeil D, Byrne M, Forbes JF (1992) Prognostic value of quality-of-life scores during chemotherapy for advanced breast cancer. Aust N Zeal Breast Cancer Trials Group J Clin Oncol 10:1833-1838. https://doi.org/10.1200/ JCO.1992.10.12.1833

Dancey J et al (1997) Quality of life scores: an independent prognostic variable in a general population of cancer patients receiving chemotherapy. Natl Cancer Inst Can Clin Trials Group Qual Life Res 6:151-158

Eisenhauer EA et al (2009) New response evaluation criteria in solid tumours: revised RECIST guideline (version 1.1). Eur J Cancer 45:228-247. https://doi.org/10.1016/j.ejca.2008.10.026

Giesinger JM et al (2016) Thresholds for clinical importance for four key domains of the EORTC QLQ-C30: physical functioning, emotional functioning, fatigue and pain Health. Qual Life Outcomes 14:87. https://doi.org/10.1186/s12955-016-0489-4

Goldhirsch A, Wood WC, Coates AS, Gelber RD, Thurlimann B, Senn HJ, Panel M (2011) Strategies for subtypes - dealing with the diversity of breast cancer: highlights of the St. Gallen International Expert Consensus on the Primary Therapy of Early Breast Cancer 2011. Ann Oncol 22:1736-1747. https://doi.org/10.1093/annonc/mdr304

Gotay CC, Kawamoto CT, Bottomley A, Efficace F (2008) The prognostic significance of patient-reported outcomes in cancer clinical trials. J Clin Oncol 26:1355-1363. https://doi.org/10.1200/ JCO.2007.13.3439

Goto W et al (2017) Circulating tumor cell clusters-associated gene plakoglobin is a significant prognostic predictor in patients with breast cancer. Biomark Res 5:19. https://doi.org/10.1186/s4036 4-017-0099-2

Howell D, Molloy S, Wilkinson K, Green E, Orchard K, Wang K, Liberty J (2015) Patient-reported outcomes in routine cancer clinical practice: a scoping review of use, impact on health outcomes, and implementation factors. Ann Oncol 26:1846-1858. https://doi. org/10.1093/annonc/mdv181

Kaasa S, Mastekaasa A, Lund E (1989) Prognostic factors for patients with inoperable non-small cell lung cancer, limited disease. The importance of patients' subjective experience of disease and psychosocial well-being. Radiother Oncol 15:235-242 
Kashiwagi S et al (2015) Partial mastectomy using manual blunt dissection (MBD) in early breast cancer. BMC Surg 15:117. https://doi. org/10.1186/s12893-015-0102-5

Kawajiri $\mathrm{H}$ et al (2012) Efficacy and feasibility of neoadjuvant chemotherapy with FEC 100 followed by weekly paclitaxel for operable breast. Cancer Oncol Lett 4:612-616. https://doi.org/10.3892/ol.2012.801

Kramer JA et al (2000) Identification and interpretation of clinical and quality of life prognostic factors for survival and response to treatment in first-line chemotherapy in advanced breast cancer. Eur J Cancer 36:1498-1506

Kurihara M, Shimizu H, Tsuboi K, Kobayashi K, Murakami M, Eguchi K, Shimozuma K (1999) Development of quality of life questionnaire in Japan: quality of life assessment of cancer patients receiving chemotherapy. Psychooncology 8:355-363. https://doi.org/10.1002/ (SICI)1099-1611(199907/08)8:4<355::AID-PON401>3.0.CO;2-I

Lee CK, Stockler MR, Coates AS, Gebski V, Lord SJ, Simes RJ, Australian New Zealand Breast Cancer Trials G (2010) Self-reported health-related quality of life is an independent predictor of chemotherapy treatment benefit and toxicity in women with advanced breast cancer. Br J Cancer 102:1341-1347. https://doi.org/10.1038/ sj.bjc. 6605649

Luoma ML et al (2003) Prognostic value of quality of life scores for time to progression (TTP) and overall survival time (OS) in advanced breast cancer. Eur J Cancer 39:1370-1376

Maisey NR, Norman A, Watson M, Allen MJ, Hill ME, Cunningham D (2002) Baseline quality of life predicts survival in patients with advanced colorectal cancer. Eur J Cancer 38:1351-1357

Mauri D, Pavlidis N, Ioannidis JP (2005) Neoadjuvant versus adjuvant systemic treatment in breast cancer: a meta-analysis. J Natl Cancer Inst 97:188-194. https://doi.org/10.1093/jnci/dji021

McShane LM, Altman DG, Sauerbrei W, Taube SE, Gion M, Clark GM, Statistics Subcommittee of the NCIEWGoCD (2005) Reporting recommendations for tumor marker prognostic studies. J Clin Oncol 23:9067-9072. https://doi.org/10.1200/JCO.2004.01.0454

Mieog JS, van der Hage JA, van de Velde CJ (2007) Preoperative chemotherapy for women with operable breast cancer. Cochrane Database Syst Rev. https://doi.org/10.1002/14651858.CD005002.pub2

Ohsumi S et al (2011) Health-related quality of life and psychological distress of breast cancer patients after surgery during a phase III randomized trial comparing continuation of tamoxifen with switching to anastrozole after adjuvant tamoxifen for $1-4$ years: N-SAS BC 03. Breast Cancer Res Treat 127:143-152. https://doi.org/10.1007/ s10549-011-1400-y

Otsuka S, Watanabe N, Sasaki Y, Shimojima R (2015) Postoperative courses of breast reconstruction using inferior adipofascial tissue repair. Breast Cancer 22:570-577. https://doi.org/10.1007/s1228 2-014-0522-6

Schouten B et al (2016) Validation of the flemish CARES, a quality of life and needs assessment tool for cancer care. BMC Cancer 16:696. https://doi.org/10.1186/s12885-016-2728-9

Schouten B et al (2017) Qualitative research on the Belgian Cancer Rehabilitation Evaluation System (CARES): an evaluation of the content validity and feasibility. J Eval Clin Pract 23:599-607. https://doi. org/10.1111/jep. 12681

Shimozuma K, Sonoo H, Ichihara K, Tanaka K (2000) The prognostic value of quality-of-life scores: preliminary results of an analysis of patients with breast cancer. Surg Today 30:255-261. https://doi. org/10.1007/s005950050055

Shiroiwa T, Fukuda T, Shimozuma K, Kuranami M, Suemasu K, Ohashi Y, Watanabe T (2011) Comparison of EQ-5D scores among anthracycline-containing regimens followed by taxane and taxane-only regimens for node-positive breast cancer patients after surgery: the N-SAS BC 02 trial. Value Health 14:746-751. https://doi. org/10.1016/j.jval.2011.01.007

Spiegel D, Bloom JR, Kraemer HC, Gottheil E (1989) Effect of psychosocial treatment on survival of patients with metastatic. Breast Cancer Lancet 2:888-891

Watanabe T et al (2009) Oral uracil and tegafur compared with classic cyclophosphamide, methotrexate, fluorouracil as postoperative chemotherapy in patients with node-negative, high-risk breast cancer: National Surgical Adjuvant Study for Breast Cancer 01 Trial. J Clin Oncol 27:1368-1374. https://doi.org/10.1200/ JCO.2008.18.3939

Wolmark N, Wang J, Mamounas E, Bryant J, Fisher B (2001) Preoperative chemotherapy in patients with operable breast cancer: nineyear results from National Surgical Adjuvant Breast and Bowel Project B-18. J Natl Cancer Inst Monogr 36:96-102. https://doi. org/10.1093/oxfordjournals.jncimonographs.a003469 